\title{
DEVELOPMENT OF A 3D DYNAMIC FLOOD WEB GIS VISUALISATION TOOL
}

\author{
S. VAN ACKERE ${ }^{1}$, H. GLAS ${ }^{2}$, J. BEULLENS ${ }^{1}$, G. DERUYTER $^{2}$, A. DE WULF $^{1} \&$ P. DE MAEYER ${ }^{1}$ \\ ${ }^{1}$ Department of Geography, Ghent University, Krijgslaan 281 (building S8), Ghent, Belgium. \\ ${ }^{2}$ Department of Civil Engineering, Ghent University, V.Vaerwyckweg 1, Ghent, Belgium.
}

\begin{abstract}
Low elevation coastal areas are vulnerable to the effects of sea level rise and to an increase in the frequency and severity of storm surge events due to climate change.Coastal urban areas are at risk because coastal flooding causes extensive damage to energy and transportation infrastructure, disruptions to the delivery of services, devastating tolls on the public's health and,occasionally, significant loss of life. Although scientists widely stress the compelling need to mitigate and adapt to climate change, public awareness lags behind. Because WebGIS maps (web-based geographic information systems) quickly convey strong messages, condense complex information, engage people on issues of environmental change, and motivate personal actions, this paper focuses on searching the ideal flood assessment WebGIS method to encourage people to mitigate and adapt to climate change. Surveys demonstrated that $3 \mathrm{D}$ visualisations have an enormous added value because they are more vivid and therefore more understandable and make it easier to imagine the consequences of a flood than2D visualisations. In this research, the WebGIS will be created using Ol3-Cesium and openlayers to visualise a flood event by dynamic layers in a 2D/3D environment.
\end{abstract}

Keywords:coastal flooding, flooding analysis, landscape visualisation, WebGIS visualisation.

\section{INTRODUCTION}

More than 634 million people, or approximately $8.7 \%$ of the world's population, live in low elevation coastal areas below $10 \mathrm{~m}$ [1,2]. A recent study published in the journal Nature reports that sea levels may rise considerably faster than expected in the coming decades because the Antarctic ice sheet is less stable than previous thought [3]. Although floodings are commonly referred to as natural disasters, they are directly attributable to the actions of human beings[4].

The Intergovernmental Panel on Climate Change (IPCC) concluded that low elevation coastal areas are vulnerable to the effects of sea level rise and an increased frequency and severity of storm surge events due to climate change[6]. Coastal urban areas are at risk because coastal flooding causes extensive damage to energy and transportation infrastructure, disruptions to the delivery of services, a devastating toll on the public's health and, occasionally, significant loss of life. At low elevation coastal areas, the wind contribution to storm surges is usually dominant compared to other forcing mechanisms as short-waves, atmospheric pressure, rainfall and river flow because the wind effect is inversely proportional to the water depth. Nevertheless, loss of human lives and property damages caused by coastal flooding are frequently larger compared to those directly related to wind [7]. 


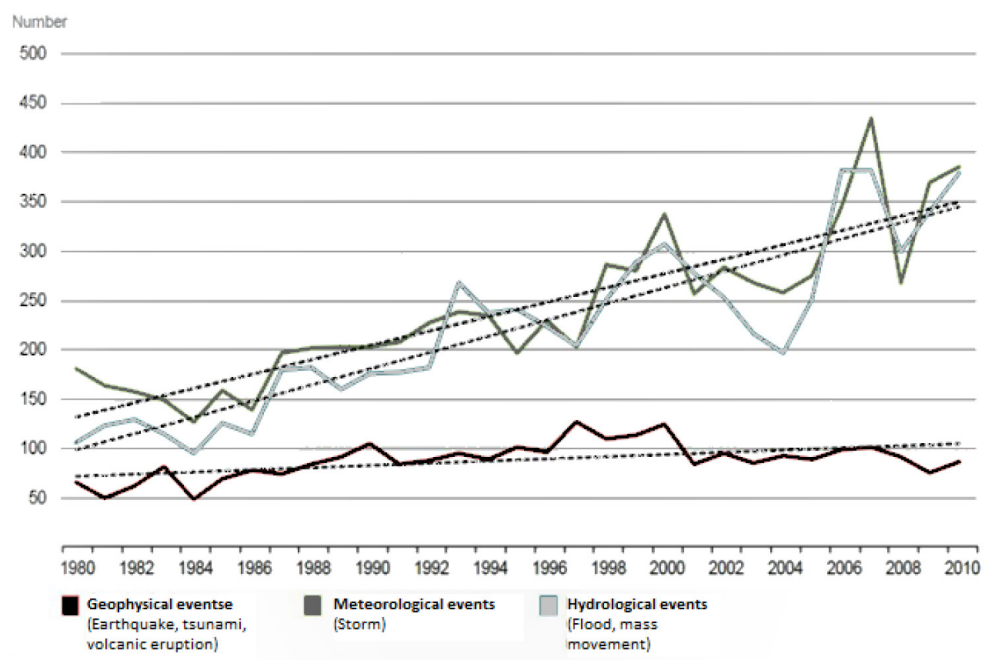

Figure 1: Natural catastrophes, worldwide (1980-2012)[5].

\section{WEB GIS FLOOD VISUALISATION}

Since the mid-1960s, numerical models have been used to investigate storm surges[8], which resulted in studies on mitigating the impacts of floods using artificial physical flood control (via the construction of dams, dykes, levees, diversion channels and related structures)[9]. To date, researchers have shown an increased interest in computational power and the advent of parallel computing, which allowed very accurate simulations of coastal floodings[7]. ZoranVojinovic emphasizes in his book 'Flood risk: the holistic perspective': "Climate change (or climate extremes), population growth and urbanisation processes are certainly bringing some of the greatest challenges of our time which in turn reinvigorate the significance of adaptation, resilience and transformation (i.e. transcendence)[4].” Although scientists widely stress the compelling need to mitigate and adapt to climate change, public awareness lags behind[10]. Therefore, there is a compelling need to inform people in low elevation coastal areas of the potential hazards with tools that quickly convey strong and clear messages of this sword of Damocles. In many cases, WebGIS applications are often used, as it quickly conveys strong messages, condenses complex information, engages people in environmental change issues, and motivates personal actions[10].In this paper, the researchers are searching for the ideal webGIS application method to visualise potential flood hazard events to engage people to adapt to climate change.

\subsection{Evaluating water level visualisation tools}

Reviewing the academic literature, considerable attention has been devoted to creating visualisation tools of sea level rise. Good examples of WebGIS of sea level rise visualisation tools are Sea Level Rise and Coastal Flooding Impacts Viewer[11], New Jersey Flood Mapper [12], Lakes Entrance Visualisation[13], Flood map Brussels[14],Explore Sahul Time [15], Interactive Sea Level Rise Web Map [16], Sea Level Rise Visualisation for AL, MS and FL[17], Surging Seas[18], What Could Disappear[19], Impacts of Sea Level Rise on the California Coast[20].These interactive WebGIS tools allow the user to visualise the sea level 
rise at a certain location, which is interesting to study when searching for the ideal WebGIS application method of flood events.

Among the many WebGIS tools, there are several tools that use incorrect methods to calculate and visualise information of sea level rise. Therefore, the most common mistake is that these tools neglect natural and artificial coastal defence infrastructures. This finding is clearly observed when the sea level is visualised for a sea level rise of $+0 \mathrm{~m}$ (see Fig. 2). Therefore, each area with an elevation lower than current sea level is visualised as areas that are flooded. This incorrect calculation can easily be corrected by only displaying areas which are physically connected with the sea. For example, when sea level rise is visualised using PostGIS, it is possible to take into account only water level polygons that are directly connected to the sea and rivers (using the function ST_ClusterIntersecting[21]). Hereby, the representation of a certain sea level rise will be correct. In addition to this incorrect visualisation, this interactive map has the misleading capture "data provided from NASA"[22], which refers to the used land elevation data and not to future sea level rise data.

It is of importance that sea level rise is well-visualised such that the inhabitants are wellinformed, allowing them to assess the seriousness of the case, although many interactive maps have the opposite effect.

\section{$2.22 \mathrm{D}$ visualisation versus $3 \mathrm{D}$ visualisation}

As already mentioned, lack of public awareness can be remedied with the use of better understandable and user friendly interactive WebGIS mapping tools. Surveys such as those conducted by Leskens (2015) showed that 3Dvisualisations have an enormous added value: "The open question about what the added value of the 3Dvisualisation was with respect to the 2Dvisualisation was answered with the following statements:

- It makes it more likely to imagine the consequences of the flood.

- It enhances prediction of what a flood would mean for an area and helps to better empathize with the situation.

- It is more realistic and detailed, and it is easier to interpret what a flood means for the area.

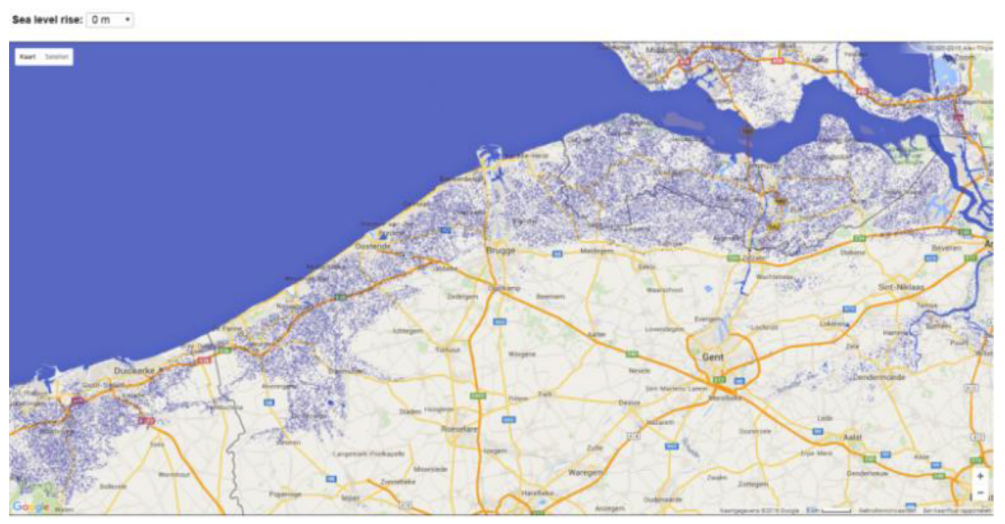

Figure 2: Examples of wrong visualisation of sea level rise [22, 23]. 
- It is more vivid and therefore more understandable.

- Less interpretation is required to estimate the consequences of the flood.

- It helps the user to better imagine how serious the flood could be.

- It better shows the consequences for the environment."[24]

3Dvisualisationhas been successfully employed for the assessment of damage to infrastructures from fire [25] and earthquakes [26]. However, despite their potential benefits for flood risk management [27],only limited efforts have been made in this area. Several studies $[24,28,29]$ have employed 3D models in flood risk management. However, the aim of these studies was merely the static 3Dvisualisation of flood hazard which was not embedded in a WebGIS tool.

A 3D map is a tremendous added value for the interpretation of a flood and for visualising reality. Nevertheless, 3D maps cannot take over all functionalities and perfect representations which is inherent to 2Dvisualisation. For example, it's easier to assess on a 2D map where the maximal contour of the flood occurs, in comparison with the estimation of the position of the maximal flood contour on a 3D map. The addition of a 2Dvisualisation together with a 3D visualisation (e.g. using a split-screen) is therefore a necessity.

\subsection{Dynamic versus static visualisation}

Many WebGIS applications make use of a single layer to visualise a sea level situation or a snapshot in time of a specific flood condition (for example, a flood condition where maximal damage to infrastructures occurs). Unfortunately, too much information gets lost by this onesided visualisation. Therefore, it is impossible to visualise the intensity or velocity of a flooding, or the rising velocity of the water on a specific location. Furthermore, it is difficult to assess how long it takes before a specific area is flooded. This information is desperately needed for evacuation and transport possibility assessments and damage to infrastructure estimation.

Therefore, there is a need for a complete turnaround and a tremendous progress in this part of visualisation methods of flooding. For visualising changes occurring (e.g.approaching hurricanes and altering wind velocity) a Web Map Service (WMS) is developed, called Time-enabled WMS layer. Time-enabled WMS layers are already used in other research areas, exhibiting the advantages of visualising altering and shifting events [30]. With this time-enabled WMS layer, it is possible to embed the output of such flood modelling software as TUFLOW, Flood Modeller, MIKE FLOOD, TELEMAC, and OpenFoam in a WebGIS environment.
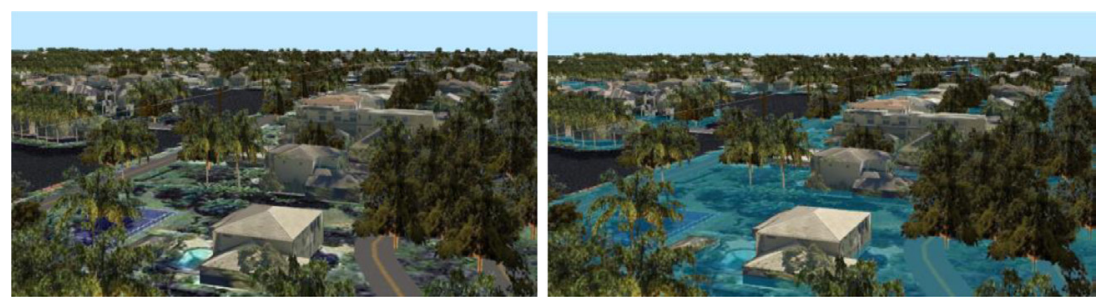

Figure 3: 3D visualisation of flooding [40]. 


\subsection{Flood damage visualisation tools}

Numerous flood damage determination and assessment tools visualise the relationship between flood depth and the maximal damage to infrastructures (e.g.[31]), whereas the intensity, horizontal velocity and rising velocity of flood events are major decisive factors to estimate the damage to infrastructures.

In addition to flood depth, damage to infrastructures has to be calculated on the basis of dynamic flood event characteristics (intensity, horizontal velocity and rising velocity). Analogous to 2.3, it's possible to visualise the damage to infrastructures in sync with the visualised dynamic flood situation. Therefore, it's possible on basis of theWebGISvisualisation tool to assess how long it takes before a certain infrastructure becomes dangerous to, for instance, enter, traverse, or pass by. Logically, the user of the WebGIS tool should also have the possibility to request the maximal damage that occurs in a specific flood event, to provide sufficient information to reach the maximal usefulness of the tool.

\subsection{Intern flood model visualisation and damage assessment}

In the past, the vast majority of researchers have not considered visualising flood infiltration inside buildings on a WebGIS application. The most likely cause of this is that a large portion of these buildings'information has to be available before it is possible to calculate the

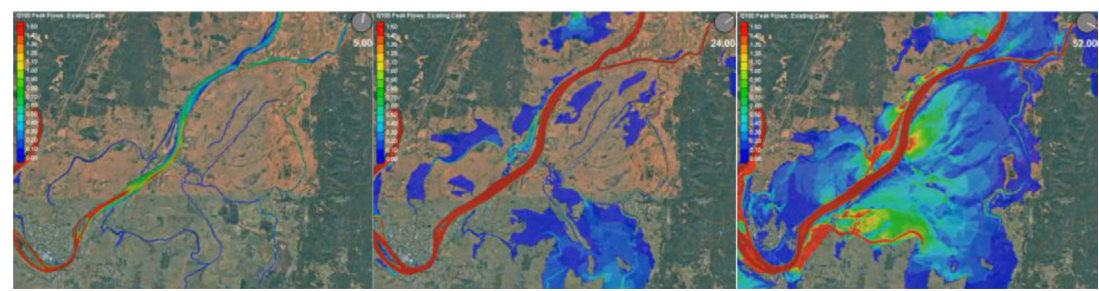

Figure 4: TUFLOW flood model simulation [32].

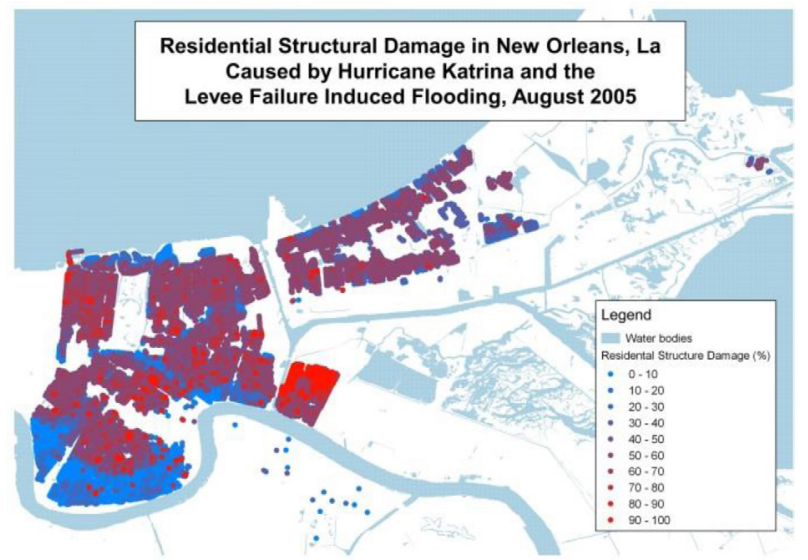

Figure 5: Example of a web-based flood damage map [33]. 
infiltration of floods and intern flood paths. When a certain flood event is modelled for a fairly large area (for example a coastal town), it is impossible to question all inhabitants to collect the necessary data of all the buildings in the area (e.g.permeability of brick walls, location of air bricks, location of pipes and cables, position of doors and windows, estimation of inadequate seals between windows, doors and frames). Subsequently, building information models (BIM) and geographical object-relational database (e.g.PostGIS) are difficult to link to each other because they have been developed separately, and they have pursued different standards and technologies. A BIM is a digital model of an existing and/or planned structure made up of objects attached with information. Thus, in addition to the geometry and position of, for example, a wall, such a model also adds such information as the construction materials (masonry or reinforced concrete), use, cost, and course of pipe work. Therefore, only a small number of researchers were able to model intern flood patterns with a geographical object-relational database in combination with a BIM [34-36]. Unfortunately, to date, there are no WebGIS tools created which visualise these intern flood patterns in buildings.

\section{DEVELOPMENT OF A 3D FLOOD VISUALISATION TOOL}

From the foregoing (see 2), it is clear that more is required to create a useful WebGIS tool for flood hazard visualisation than onlyvisualising static 2D layers. For instance, to make it easier to imagine the consequences of a flood and making a map more realistic and detailed, an additional 3Dvisualisation of the landscape (for example in the form of a split screen) is needed. To make a realistic 3D flood visualisation tool in this research,Ol3-CesiumOpenlayers is used [37, 38]. O13-Cesium is written in Javascript, uses WebGL. WebGL and is an open standard for visualising3D-computer graphics in a webpage without using special plug-ins for web browsers.

This O13-Cesium web library adds 3Dvisualisation to an OpenLayers3 map by automatically creating a virtual globe side-by-side the existing OpenLayers 3 map. When manipulating the OpenLayers3 map (zooming, panning, etc.) the synchronised Cesium virtual globe follows automatically. The globe camera and the map view (centre, resolution, rotation) are bidirectionally synchronized: interacting with one updating the other. Layers are synchronized from the openlayers3map. Additionally, ol3 vector layers render on the Ol3-cesium screen using the same style and is displayed in the $3 \mathrm{D}$ environment.

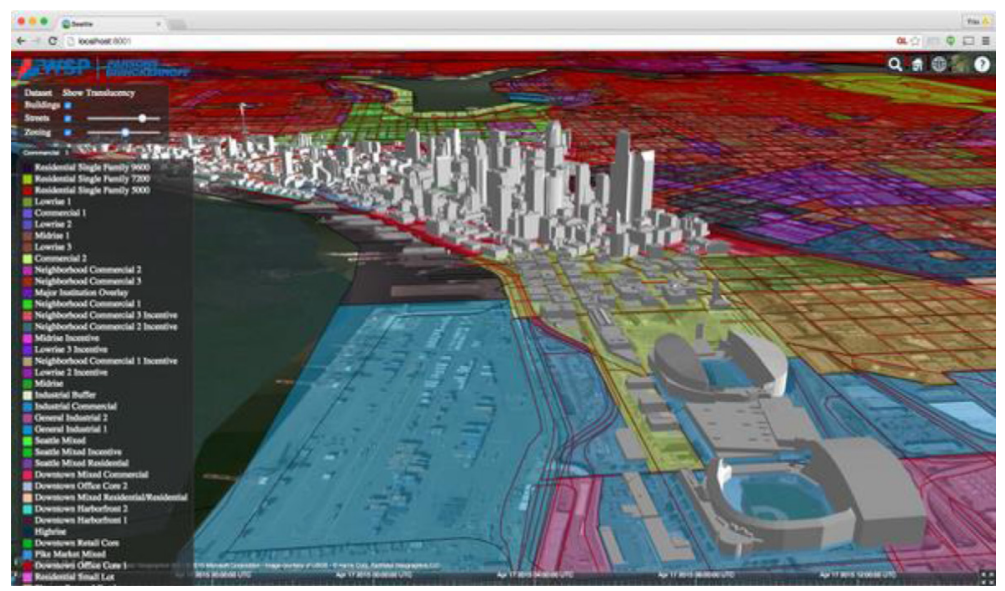

Figure 6: Example O13-Cesium web-based map [37]. 
In November of 2014, the OpenWebGIS group published a WebGIS tool where Atlantic hurricane tracks shown from 1851-2004 using time-enabled layers in the Ol3-Cesium environment[30]. Unfortunately, the user was forced to identify an interval before its visualized layer was available instead of showing the successive layers using a play button. Research has yet to prove that it is possible to visualisetime-enabled WMS layer in the 3DOl3-cesium (see 2.3) environment whereby dynamic flood events can be visualised.

\section{CONCLUSIONS}

Although scientists widely stress the compelling need to mitigate and adapt to climate change, public awareness lags behind that of scientists. Because WebGIS maps quickly convey strong messages, condense complex information, engage people on issues of environmental change, and motivate personal actions, this paper focusses on searching the ideal flood assessment WebGISmethod to encourage people to mitigate and adapt to climate change. In comparison with other WebGIS tools, many WebGIS applications make use of a single layer to visualise a sea level situation or a snapshot in time of a specific flood condition. Unfortunately, too much information is lost by this one-sided visualisation.

Surveys such as that conducted by Leskens (2015) showed that 3D visualisations have an enormous added value.These findings suggest that 3D condenses more complex information, and conveys strong messages quicker than2D. Nevertheless, 3D maps cannot take over all functionalities and perfect representations, which is inherent to $2 \mathrm{D}$ visualisation. For example, it is easier to assess on a 2D map where the maximal contour of the flood occurs in comparison with the estimation of the position of the maximal flood contour on a 3D map. The addition of a $2 \mathrm{D}$ visualisation together with a $3 \mathrm{D}$ visualisation (for example by using a split-screen) is therefore a necessity.

Analogous to the dynamic visualisation of a flood event, it is possible to visualise the damage to infrastructures in sync with the visualised dynamic flood situation. Therefore, it is possible to assess how much time is required before a certain infrastructure is dangerous to, for instance, enter, traverse, or pass by on the basis of the WebGIS visualisation tool.

In this research, the initial steps have been taken to create a WebGIS tool that visualises property damages caused by coastal flooding and flood events themselves in a 2D/3Dol3cesium environment. Dynamic time-enabled WMS layers will visualise flood events, whereby the user can imagine how serious the flood will be. This tool will be elaborated during the CREST-project [39] in the future. This ideal webGIS application will visualise potential flood hazard events to engage people to adapt to climate change in the future.

\section{ACKNOWLEDGEMENT}

This paper is written in the framework of the research project CREST (Climate REsilientcoaST) [39]. This project aims to increase resilience of coastal flooding caused by extreme weather events.

\section{REFERENCES}

[1] Lichter, M., Vafeidis, A.T., Nicholls, R.J.\&Kaiser, G.,Exploring data-related uncertainties in analyses of land area and population in the "Low-Elevation Coastal Zone" (LECZ). Journal of Coastal Research,27, pp. 757-68, 2010.

[2] McGranahan, G., Balk, D.\&Anderson, B.,The rising tide: assessing the risks of climate change and human settlements in low elevation coastal zones. Environment\&Urbanization,19, pp. 17-37, 2007. doi:10.1177/0956247807076960. http://dx.doi.org/10.1177/0956247807076960 
[3] Deconto, R.M.\&Pollard, D.,Contribution of Antarctica to past and future sea-level rise. Nature, 531, pp. 591-597, 2016. doi:10.1038/nature17145.

http://dx.doi.org/10.1038/nature17145

[4] Vojinovic, Z.,Flood Risk: The Holistic Perspective. vol. 1. London IWA Publishing: London, 2015.

[5] Re, M.,Natural disaster - Annual statistics 2015,available at: http://www.munichre.com/ en/reinsurance/business/non-life/natcatservice/annual-statistics/index.html (accessed 15 March 2016).

[6] Nicholls, R.J., Wong, P.P., Burkett, V.R., Codignotto, J.O., Hay, J.E., McLean, R.F., SR and CDW. Coastal systems and low-lying areas. Climate Change 2007: Impacts, Adaptation and Vulnerability. Contribution of Working Group II to the Fourth Assessment Report of the Intergovernmental Panel on Climate Change, Cambridge, UK, 2007.

[7] Bertin, X., Li, K., Roland, A., Zhang, Y.J., Breilh, J.F.\&Chaumillon,E.,A modelingbased analysis of the flooding associated with Xynthia, central Bay of Biscay.Coastal Engineering.94, pp. 80-89, 2014, doi:10.1016/j.coastaleng.2014.08.013.

http://dx.doi.org/10.1016/j.coastaleng.2014.08.013

[8] Jelesnianski, C.P.,A numerical calculation of storm tides induced by a tropical storm impinging on a continental shelf. Monthly Weather Review,93, pp. 343-358, 1965. doi:10.1175/1520-0493(1993).

[9] Sayers, P., Yuanyuan, L., Galloway, G., Penning-Rowsell, E., Fuxin, S., Kang, W., et al. Flood Risk Management: A Strategic Approach, UNESCO: Paris, 2013.

[10] Sheppard, S.R.J.,Landscape visualisation and climate change: the potential for influencing perceptions and behaviour. Environmental Science\&Policy,8, pp. 637-654, 2005. doi:10.1016/j.envsci.2005.08.002.

http://dx.doi.org/10.1016/j.envsci.2005.08.002

[11] NOAA Coastal Services Center. Sea Level Rise and Coastal Flooding Impacts 2015, available at: https://coast.noaa.gov/slr/ (accessed March 29, 2016).

[12] JCNERR, CRSSA, NOAA CSC SN, Rutgers University. Sea Level Rise and Coastal Flooding Impacts 2015, available at: http://54.243.129.238/SLR.html\# (accessed 29 March 2016).

[13] Monash University. Lakes Entrance Flood-Risk Visualisation n.d,available at: http:// sahultime.monash.edu.au/LakesEntrance/ (accessed 29 March 2016).

[14] Leefmilieu Brussel. Overstroming n.d,available at: http://geoportal.ibgebim.be/webgis/ Overstroming_kaart.phtml (accessed 11 April 2016).

[15] Monash University. Explore SahulTime n.d,available at: http://sahultime.monash.edu. au/explore.html (accessed 29 March 2016).

[16] SBEP \& MOTE Marine Laboratory. Interactive Sea Level Rise Web Map n.d. available at: http://geology.com/sea-level-rise/florida.shtml (accessed 29 March 2016).

[17] NOAA-MS-AL Sea Grant U. Sea Level Rise Visualization for AL, MS, \& FL n.d. available at: http://gom.usgs.gov/slr/slr.aspx (accessed March 29, 2016).

[18] Climate Central. Surging Seas: Risk Zone Map, n.davailable at: http://ss2.climatecentral.org/\#12/40.7298/-74.0070? show=satellite \&projections=0 - RCP85SLR\&level=5\&unit=feet\&pois=hide (accessed 29 March 2016).

[19] NY Times. What Could Disappear n.d,available at: http://www.nytimes.com/interactive/2012/11/24/opinion/sunday/what-could-disappear.html?_r=0 (accessed 29 March 2016).

[20] Pacific Institute. Pacific Institute: Sea-Level Rise 2009,available at: http://www2.pacinst.org/reports/sea_level_rise/gmap.html (accessed 29 March 2016). 
[21] PostGIS community. ST_ClusterIntersecting n.d. available at: http://postgis.net/docs/ ST_ClusterIntersecting.html (accessed 29 March 2016).

[22] Tingle, A.,Flood Maps n.d,available at: http://flood.firetree.net/?ll=48.3416,14.6777\&z $=13 \& \mathrm{~m}=7$ (accessed 29 March 2016).

[23] Burle, S.,Flood Map: Water Level Elevation Map n.d. available at: http://www.floodmap.net/?1l=51.256222,4.120335\&z=9\&e=0 (accessed 29 March 2016).

[24] Leskens, J.G., Kehl, C., Tutenel, T., Kol, T., de Haan, G.,Stelling, G., et al. An interactive simulation and visualization tool for flood analysis usable for practitioners. Mitigationand Adaptation Strategiesfor Global Change, 2015. doi:10.1007/s11027-015-9651-2. http://dx.doi.org/10.1007/s11027-015-9651-2

[25] Ruppel, U.\&Schatz, K.,Designing a BIM-based serious game for fire safety evacuation simulations.Advanced Engineering Informatics,25, pp. 600-611, 2011. doi:10.1016/j. aei.2011.08.001.

http://dx.doi.org/10.1016/j.aei.2011.08.001

[26] Christodoulou, S.E., Vamvatsikos, D.\&Georgiou, C.,A BIM-based framework for forecasting and visualizing seismic damage, cost and time to repair. eWork and ebusinessin Architecture Engineeringand ConstructionECPPM 2010,CRC Press: Boca Raton, 2010:33-38.

[27] Isikdag, U.,A SWOT analysis on the implementation of building information models within the geospatial environment. Urban and Regional Data Management: UDMS Annual, Taylor \& Francis: London, pp. 15-30, 2009.

[28] Kemec, S., Zlatanova, S.\&Duzgun, H.S.,A framework for defining a 3d model in support of risk management. Geographic Informationand Cartographyfor Risk and Crisis Management,pp. 69-82,2010, doi:10.1007/978-3-642-03442-8.

http://dx.doi.org/10.1007/978-3-642-03442-8

[29] Mioc, D., Anton, F., Nickerson, B., Santos, M., Adda, P., Tienaah, T., Ahmad, A., Mezouagh, M., MacGillivray AM and PT. Flood progression modelling and impact analysis. Gi4DM (Geoinformation Disaster Manag. Conf., 2011.

[30] OpenWebGis. Atlantic Hurricane Tracks with OpenWebGIS n.d. available at: https:// www.youtube.com/watch?v=y0UAV9jYsXc (accessed April 11, 2016).

[31] Pistrika, A.,Flood damage estimation based on flood simulation scenarios and a GIS platform. European Water,30, pp. 3-11, 2010.

[32] TUFLOW n.d. available at: http://www.tuflow.com/ (accessed 4 April 2016).

[33] Disastermap. Residential structural damage in New Orleans n.d. available at: http:// disastermap.net/wordpress/wp-content/uploads/2015/08/Residential-Damage-Points. jpeg (accessed 12 April 2016).

[34] Amirebrahimi, S., Rajabifard, A., Mendis, P.\&Ngo, T.,A framework for a microscale flood damage assessment and visualization for a building using BIM-GIS integration. International Journalof DigitalEarth,1-24, 2015. doi:10.1080/17538947.2015.1034201. http://dx.doi.org/10.1080/17538947.2015.1034201

[35] Amirebrahimi, S., Rajabifard, A., Mendis, P.\&Ngo, T.,A data model for integrating GIS and BIM for assessment and 3D visualisation of flood damage to building.CEUR Workshop Proceeding, 1323, pp. 78-89, 2015.

[36] Varduhn,V. \& Mundani R.P.\&Rank, E., Multi-resolution models: recent progress in coupling $3 \mathrm{~d}$ geometry to environmental numerical simulation. In: 3D Geoinformation Science,eds. M. Breunig,M. Al-Doori, E. Butwilowski, P.V. Kuper, J. Benner \&K.H. Haefele, Springer International Publishing,pp. 55-69, 2015. doi:10.1007/978-3-31912181-9.

http://dx.doi.org/10.1007/978-3-319-12181-9 
[37] Cozzi, P., 3D Buildings in Cesium n.d,available at: http://cesiumjs.org/2015/04/27/3DBuildings-in-Cesium/ (accessed 8 April, 2016).

[38] Cozzi, P.,Ol3-Cesium by openlayers n.d,available at: http://openlayers.org/ol3-cesium/ (accessed 8 April 2016).

[39] Flanders Innovation \& Entrepreneurship. Climate Resilience Coast - CREST 2015, available at: http://www.crestproject.be/en (accessed 12 April 2016).

[40] DeVito K. Assessing Flood Risk with 3D GIS - A NEMAC study of Ft. Lauderdale 2015. https://www.linkedin.com/pulse/assessing-flood-risk-3d-gis-nemac-study-ft-kevin-devito. 